\title{
Expertos en comunicación y moda. Calidad profesional en tiempos de crisis
}

\author{
Recibido: 22 de octubre de 2012 \\ Aceptado: 06 dejunio de 2013 \\ Publicado: 29 de noviembre de 2013
}

\author{
Concha Pérez Curiel \\ cperez1@us.es
}

Universidad de Sevilla (España)

\begin{abstract}
Resumen: En el ámbito de la información periodística especializada, la moda ocupa un espacio cada vez más protagonista. La demanda de los futuros profesionales de los medios requiere conocimiento, profundización y práctica para contrarrestar la presencia de fuentes interesadas e intrusas, que anulan el papel del Fashion Journalist. La presente investigación se plantea aspectos como la ausencia de formación universitaria de periodistas especializados en moda, la falta de calidad en los textos periodísticos, así como las perspectivas empresariales y laborales en el sector de la comunicación y la moda. El análisis de contenido, basado en la herramienta VAP (Valor Añadido Periodístico) que mide la calidad informativa junto con la realización de entrevistas personales dirigidas a fuentes especializadas en moda, compone el corpus metodológico de la investigación.
\end{abstract}

Palabras clave: Comunicación, moda, emprendedores, calidad, universidad, VAP.

\begin{abstract}
In the area of specialized news reporting, fashion occupies an increasingly role. The demand of the next media professional requires knowledge, deepening and practice to offset the presence of interested and intruder sources, which annul the role of the Fashion Journalist. This investigation is based on aspects like the lack of fashion specialized journalists formation, the lack of quality inside the journalistic texts and also the perspectives of new companies and work inside the Fashion Communication sector. The content analysis based on the VAP Tool (Value Added Journalism) that measures the quality of the information and also the making of personal interviews directed to specialized fashion sources that composes the methodological corpus of the investigation.
\end{abstract}

Key words: Communication, Fashion, Entrepeneurs, Quality, University, VAP. 


\section{Introducción}

\subsection{Formación, moda y medios de comunicación}

Es conocida la animadversión del diseñador Balenciaga con la prensa. Nunca quiso aparecer en los medios de comunicación, se ha dicho a causa que de una experiencia negativa en sus primeros años. Balenciaga rehuía de las fotos y sólo concedió una única entrevista a The Times en 1971, tres años después de su retirada de la Alta Costura (Figueras, 2005: 259). Sin embargo, cada vez se convocan más ruedas de prensa y se publican más crónicas, críticas, entrevistas o reportajes en suplementos, revistas especializadas o páginas de "Cultura" y "Sociedad", sin olvidar a articulistas y columnistas que dedican su hiriente o loable discurso a la moda y a sus protagonistas.

La teoría principal que avala sus críticas es el desconocimiento que la prensa y el audiovisual tienen de aspectos técnicos, de lenguaje especializado, de trayectoria de sus creativos, de estructuras y sociedades implicadas, de inversiones, productos y beneficios, de catalogación profesional... en definitiva, la desinformación sobre un mundo que cada vez ocupa más espacio mediático y genera más debate social. En España, la información sobre moda tiene aún un largo camino por recorrer. En general existen pocos periodistas especializados en la materia e incluso las crónicas de moda están firmadas por personas que proceden de ámbitos distintos al periodístico.

Como profesora de Periodismo Especializado, sorprende que sean numerosos los alumnos a los que les atrae esta temática, quizás porque han detectado esa laguna formativa en la prensa de información general e incluso en las revistas especializadas, quizás deseosos de emprender, de crear empresas de comunicación ligadas al sector de la moda. Pero, ¿interesa a los pope de la comunicación la información sobre moda? ¿Qué ingresos están en juego? ¿Qué perfil de periodistas cubren estos acontecimientos? ¿Se utilizan estos temas para ocultar otros que afectan a la opinión pública?

Figura 1: Portafolio.

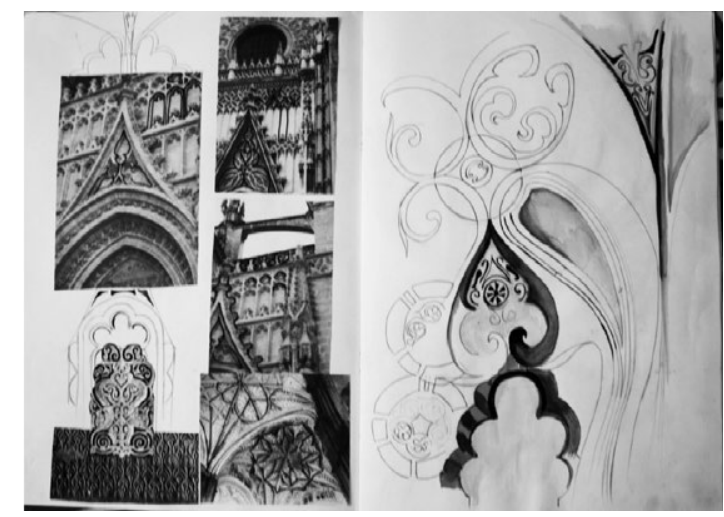

Fuente: Central Saint Martins, University of The Arts London. 
Y en el ámbito universitario, ¿qué opciones se otorgan en los nuevos planes a la especialización? ¿En qué medida se da respuesta a la demanda de jóvenes que apuestan por un tema de interés económico y social como la moda? ¿Se entiende la moda como algo frívolo, superficial, ligado al elitismo de las celebrities?

En la universidad recae la responsabilidad de diseñar un perfil profesional de periodista experto en moda, de fomentar la investigación, de ofrecer acceso a documentación y bibliografía específica y generar nuevas publicaciones; de enseñar con la colaboración de los medios y de los especialistas un mundo que sobrepasa los límites del diseño para adentrarse en el mundo de la comunicación, de la empresa, del marketing, de las redes sociales...

En los medios es preciso tratar los acontecimientos sobre moda siguiendo las pautas de un buen trabajo periodístico, incluyendo background, contextualización, explicación, interpretación, lenguaje técnico, juicios de valor... Y para ello hace falta una formación desde el conocimiento en profundidad de la historia y la cultura de la moda, de las tendencias, de las fuentes, del lenguaje técnico y de géneros como la crónica o la crítica que evidencian el arte de contar la moda.

\subsection{La universidad de la moda}

El mundo de la moda en España ha pasado de ser un ámbito exclusivo de revistas especializadas y élites sociales a ocupar un espacio relevante en los diarios de información general. Este proceso de cambio no es directamente proporcional al número y calidad de periodistas expertos en la materia. Hasta hace poco, las crónicas de moda, la cobertura de eventos relacionados o las entrevistas a diseñadores y expertos estaban firmadas por periodistas de la redacción que desconocían el tema y se ocupaban puntualmente de la noticia. Esta situación crea malestar entre los expertos de la moda que critican la falta de documentación, de información, de lenguaje técnico o la visión sensacionalista y frívola con que los medios tratan a menudo los temas sobre moda. Sin embargo, el seguimiento de la prensa y también de la radio y la televisión constata que existe un interés cada vez mayor del público por estos temas, una demanda a la que también los medios intentan responder.

En contraposición, no ha crecido tanto la oferta de las universidades españolas para formar a periodistas expertos en moda. Las universidades más prestigiosas son de ámbito internacional: Londres (Central Saint Martin), Nueva York (Parsons y FIT), París (La Chambre) o Milán (Marangoni)... en su mayoría del ámbito privado y cuentan con una oferta mucho mayor para estudiantes de comunicación que quieren especializarse en moda.

El mercado de la moda, las grandes empresas, sociedades y grupos de accionistas están también vinculados a estos centros de la moda, lo que genera también mayor cantidad de información en los medios de comunicación. Es relevante el espacio diario que los periódicos y revistas dedican a la moda en un foco comercial como Nueva York o el que dedican los medios británicos a una actividad formativa de alto nivel como la de Londres. 
Una ecuación, por tanto, en la que X e Y (universidad y medios) son un tándem necesario para formar y comunicar la moda ${ }^{1}$.

Dista mucho una información que elabora el periodista a partir de una relación directa con las fuentes especializadas (diseñadores, modelos, ilustradores, estilistas, responsables de comunicación y marketing de empresa) de aquella otra centrada exclusivamente en el sensacionalismo, la "prensa del corazón" o la "telebasura". Sin embargo, es difícil prescindir de personajes de reconocida fama y popularidad en los medios de comunicación que son la imagen de moda, las musas, el glamour para los creativos del diseño.

El periodista debe saber trasladar a sus lectores, a su audiencia, las connotaciones que rodean a este ámbito del arte. ¿Es la moda una alternativa sólo accesible a esferas sociales de alto nivel? ¿Qué estrategias se siguen para acercar la moda a la gente de la calle? ¿En qué manos se sustenta el imperio de la moda? ¿Qué tópicos rodean a las modelos? ¿Qué hay de cierto en definirlas como víctimas de su propia imagen?

La labor del periodista especializado no es sólo informar sino también formar a los públicos en la medida que promueve una actitud crítica y reflexiva ante la información. Es difícil obviar el interés de los medios por inundar de moda cualquier espacio televisivo (con cadenas en las que hay monográficos de moda que se suceden a lo largo de todo el día, magazines que dedican gran parte de su tiempo a mostrar a los famosos asistiendo a pasarelas de renombre como las de París, Milán, Londres o Nueva York, sin desestimar las españolas de Cibeles o Gaudí; o a tratar la moda desde el punto de vista del consumismo y de las fashions victims, las compulsivas compradoras que también han tenido su hueco en el cine con películas como Sexo en Nueva York, El diablo viste de Prada o Confesiones de una compradora compulsiva) o de prensa (con crónicas de moda ilustradas con fotografías a color y grandes titulares) o la gran apuesta por la especialización en las reconocidas revistas de moda, dirigidas a un sector femenino y ya también masculino, interesado en conocer las últimas tendencias.

La simbiosis entre expertos y periodistas para divulgar la moda no es sólo recomendable sino necesaria porque es un derecho de los ciudadanos y un deber de los medios dar servicio y respuesta a la demanda de los públicos desde una perspectiva IFE (Información, Formación y Entretenimiento).

\section{Objetivos}

Se pueden considerar objetivos de la investigación los siguientes:

1 En el curso 2012-2013 ha iniciado su trayectoria el primer Máster de Comunicación, Moda y Empresa en la Universidad de Sevilla, para responder a la demanda de futuros periodistas y expertos en moda que buscan formación, pero también una alternativa para crear empresa y empleo. 
- Comprobar la relación entre la calidad del texto periodístico y la formación académica y profesional del periodista que la produce.

- Conocer la cantidad y calidad de la información sobre moda publicada en los diarios españoles.

- Comparar la publicación de temas de moda entre diarios del ámbito nacional e internacional.

- Averiguar si la firma de textos publicados corresponde a periodistas especializados en moda o si, por el contrario, se vincula a cualquier profesional mediático o incluso a expertos y colaboradores externos a los medios.

- Analizar la oferta formativa en comunicación y moda en universidades españolas y extranjeras.

- Reflexionar sobre la trayectoria en formación especializada en moda en el contexto de determinadas universidades extranjeras y su proyección en la oferta de empleo, y la creación de empresas en el sector en comparación con el contexto español.

\section{Hipótesis de la investigación}

Inicialmente y atendiendo a las dos fases que constituyen el corpus de la investigación se puede establecer una serie de hipótesis. La medición de calidad de los contenidos en distintos medios de comunicación (de ámbito nacional e internacional) nos permitirá comprobar, mediante la aplicación de una ficha, las siguientes hipótesis:

- La información sobre moda es aún una asignatura pendiente en los medios de información general.

- Los textos periodísticos sobre moda, publicados en los diarios de información general, no cumplen los niveles de calidad referentes al periodismo especializado.

- El periodista que firma la información sobre moda no es un profesional especializado y formado en la materia, sino que procede de cualquier otro ámbito temático.

Hipótesis relativas a la segunda fase de la investigación son:

- Una adecuada formación especializada en el ámbito de la comunicación y la moda es una herramienta indispensable para incrementar el porcentaje de profesionales en el mercado laboral.

- El nivel de calidad del texto periodístico es directamente proporcional al nivel de formación del profesional que lo firma.

- La formación especializada en moda en universidades extranjeras alcanza porcentajes muy superiores en comparación con la ofrecida en las universidades españolas.

\section{El método. De la encuesta al análisis de contenido}

Nuestro proyecto investigador cuenta con una trayectoria que se remonta al año 2009, a raíz de la asistencia a un congreso y posterior estancia de investigación en la Universidad Sacro Cuore de Milán donde comienza el interés por profundizar en un tema que, como 
perspectiva profesional, demandan muchos de los estudiantes de Periodismo Especializado de la Universidad de Sevilla.

El primer paso será la elaboración de encuestas a diferentes sectores vinculados al mundo de la comunicación y la moda. Diseñadores, modelos, redactores de revistas especializadas en moda y alumnos universitarios. La baremación de resultados muestra del lado de los expertos un rechazo generalizado al trabajo periodístico calificado de superficial, descontextualizado, poco documentado y sensacionalista, colaborando con la difusión ante los públicos de una imagen de la moda frívola, materialista y proscrita en el ámbito universitario.

Del lado de los medios de comunicación, la información sobre moda en general se considera algo puntual, que se atiende con un periodista generalista (curiosamente "chica con estilo" que "viste bien" y que propone ser quien cubra la noticia) y que únicamente cuenta con una cobertura especial cuando determinados eventos lo exigen dentro de la crónica social del periódico o programa de televisión o radio. Por último, los alumnos universitarios encuestados en general reconocen el interés de especializarse en el sector como posible alternativa al existir una falta evidente de expertos en la materia, así como un deficiente nivel de calidad informativa.

Paralelamente a estas encuestas, y como avance de la investigación, comienza a estudiarse junto con profesores de la Universidad Sacro Cuore de Milán los contenidos periodísticos sobre moda en periódicos españoles e italianos con objeto de comprobar en qué medida el tema, la asiduidad, la ubicación en secciones, el tratamiento, el uso de las fuentes, del lenguaje y de los géneros responden a niveles de calidad en contextos diferentes en su relación con la moda. Es este el momento en el que la investigación entronca con el trabajo de nuestro grupo de investigación "Estudio de Medios para un Periodismo de Calidad" en el que tiene cabida la aplicación de una herramienta básica para medir, cualitativa y cuantitativamente, los contenidos periodísticos. Una coincidencia en el tiempo que ha enriquecido nuestro trabajo inicial.

\subsection{Método VAP. Pasarela de calidad}

¿Cómo distinguir un trabajo periodístico de calidad frente a otros que no cumplen los parámetros mínimos exigidos? ¿Es la calidad informativa un factor que ayude a desvincular de la moda términos como frivolidad o superficialidad?

Que la moda ocupe un lugar para el estudio dentro de los muros de la universidad, emblema de academia e investigación, no ha sido fácil. En el marco europeo existen países con una gran trayectoria en Fashion Research como Londres, Milán o París que albergan un gran número de centros universitarios públicos y privados dedicados al estudio de la moda. En España empieza a ser una alternativa académica y profesional para un sector importante de alumnos. En lo que se refiere al campo de la comunicación, es bastante más de un $40 \%$ de los encuestados (procedentes del ámbito del periodismo, la publicidad o el audiovisual) no descartaría dedicarse en un futuro al ámbito temático de la moda.

Sin embargo, el análisis de la prensa de información general (exceptuando suplementos y revistas especializadas) demuestra un tratamiento puntual y superficial de los contenidos 
sobre moda, carentes de ubicación fija en el periódico (sección) y de documentación, fuentes y lenguaje que garanticen la calidad del género y del profesional que lo firma.

Figura 2: Artículo en revista especializada de moda.

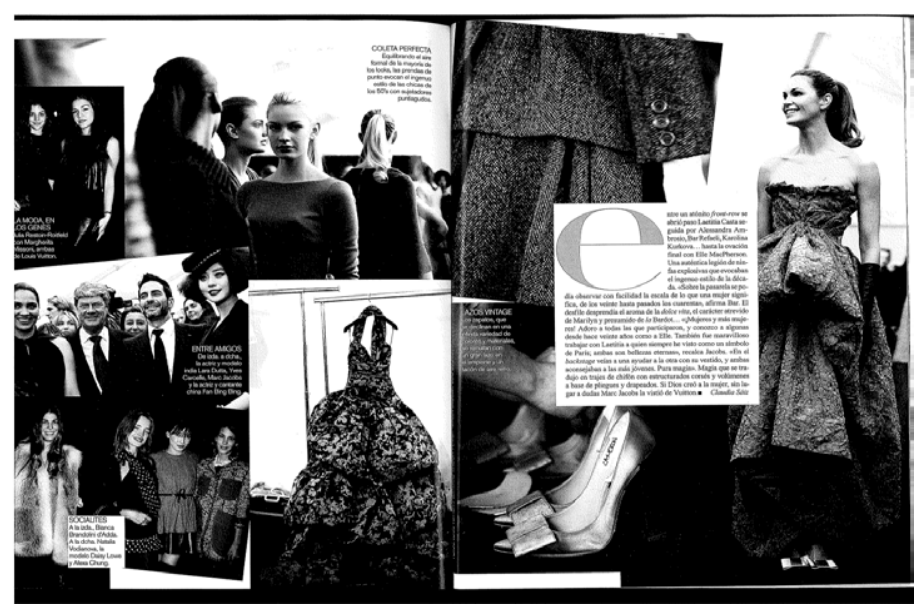

Fuente: Claudia Sáiz (Revista Vogue España).

Propuestas como la conducida por los profesores Gómez Mompart y Palau Sampío (2013) tiene como finalidad sentar las bases para un método de análisis de la calidad de las producciones periodísticas que combine los aspectos textuales y contextuales, es decir, no sólo aquellos derivados del producto final sino también los que están relacionados con las condiciones de producción, de modo que pueden interpretarse posibles intereses en la inclusión y tratamiento de determinadas noticias.

El artículo de García Gordillo, Bezunartea Valencia y Rodríguez Cruz (2012) entiende que la definición de calidad periodística basada en principios deontológicos como veracidad, contraste, coherencia y equidad tropieza con condicionamientos económicos, ideológicos y laborales-profesionales. Así, con frecuencia se designan como periodísticos productos que sólo cumplen algunas condiciones de lo noticiable (ser algo novedoso, llamativo) pero que omiten otros requisitos básicos como veracidad, interés público, contexto, contraste. Cabe pues plantearse cómo reconocer el periodismo de calidad.

Nuestro grupo de investigación, "Estudio de Medios para un Periodismo de Calidad", ha rescatado un instrumento de medición de la calidad de los textos periodísticos mediante la aplicación del Método VAP ("Valor Agregado Periodístico"), que permite analizar el tratamiento de los textos periodísticos no sólo a nivel cuantitativo sino cualitativo. El objetivo global del proyecto es averiguar cuáles son los niveles que determinan que un trabajo periodístico pueda considerarse de calidad y si esa calidad está ligada o no a la figura del profesional, es decir, habrá que ver qué relación existe entre calidad de la información y perfil de la profesión. El método VAP, desarrollado en la Pontificia Universidad Católica de Chile y de Argentina, es un verdadero hallazgo para evaluar de un modo objetivo la calidad 
del trabajo periodístico y así se ha puesto de manifiesto en múltiples investigaciones. Esta metodología evalúa los textos periodísticos en función de un proceso de selección de la noticia (gatekeeping) y un proceso de creación de la misma (newsmaking). El proceso consiste en la aplicación de fichas de análisis al texto primero en la fase de selección del acontecimiento y posteriormente en su desarrollo y jerarquización.

Un buen periodista que cubre la información sobre moda debe ser a su vez un buen investigador, documentalista y crítico del tema. En España todavía hoy la información sobre moda se reduce a las fechas de celebración de las Fashion Week Internacionales y por supuesto a la española Mercedes Fashion Week. Después, son contadas las páginas dedicadas a la moda, salvando algunas crónicas de edición fija, cuyas firmas ni siquiera corresponden a periodistas, sino a personas vinculadas con el mundo de la moda.

Es hora de que los periodistas expertos reivindiquen un espacio para dotarlo de contenido y calidad. La ficha $\mathrm{VAP}^{2}$ permitirá medir una labor profesional de referencia: la del periodista de moda. El modelo estándar de ficha de análisis es el que ahora se presenta, aunque sujeto a las modificaciones propias del desarrollo de la investigación:

Proceso de selección:

- Indicadores de selectividad: Con respecto al tipo de noticia, al origen y a la relevancia del hecho respecto al público.

- Indicadores de acceso: Con respecto a la presencia de las fuentes, número, tipo (gubernamental, oficial pública, oficial privada, experto, testimonial y no identificada) y los niveles de contraste y verificación de las mismas.

- Indicadores de equidad: Con respecto a la presencia del protagonista de la noticia, del antagonista y de la temática central de la información.

Proceso de creación:

- Indicadores de estilo: Lo que se corresponde más con un análisis de los recursos formales que pueden incidir también en la contextualización y complementación de los contenidos. Estos indicadores hacen referencia al tipo de estructura (pirámide invertida, estructura cronológica, mixta o de género), a la presencia del periodista narrador, al número de adjetivos, de verbos, de fotos, de infográficos, gráficos...

- Indicadores de contenido: Claves para conocer el nivel de documentación, de explicación, de análisis, de profundidad, de crítica razonada que usa el periodista. Por tanto es fundamental la localización de los antecedentes (background), las consecuencias y la observación del periodista ante los hechos.

- Indicadores de énfasis: Centrados en el enfoque inicial (de conflicto, de interés humano

2 El modelo de ficha tiene su origen en el trabajo desarrollado por expertos de la Pontificia Universidad Católica de Chile y Argentina, uno de cuyos miembros forma parte de nuestro grupo de investigación. 
o trascendencia) y en el tratamiento fáctico, especulativo, sensacionalista que se detecta en la información.

Aunque el grupo de investigación ha delimitado el estudio a los textos en formato digital, en este caso la ficha se ha aplicado a los diarios de información general. Como se puede comprobar, se trata de un recurso que permite medir cuantitativa y cualitativamente las marcas que presenta una noticia, un reportaje, una crónica o una crítica sobre moda.

\section{Marco teórico}

El mundo de la moda en España ha pasado de ser un ámbito exclusivo de revistas especializadas y élites sociales a ocupar un espacio cada vez más relevante en los diarios de información general. Este proceso de cambio no es directamente proporcional al número y calidad de periodistas expertos en la materia. Hasta hace poco, las crónicas de moda, la cobertura de eventos relacionados o las entrevistas a diseñadores y expertos estaban firmadas por periodistas de la redacción que desconocían el tema y se ocupaban puntualmente de la noticia. Esta situación crea malestar entre los expertos de la moda que critican la falta de documentación, de información, de lenguaje técnico o la visión sensacionalista y frívola con que los medios tratan a menudo los temas sobre moda. Sin embargo, el seguimiento de la prensa (y también de la radio y la televisión) constata que existe un interés cada vez mayor del público por estos temas, una demanda a la que también los medios intentan responder.

En contraposición, no ha crecido la oferta de las universidades españolas para formar a periodistas expertos en moda, una alternativa a tener en cuenta dada la atención que despiertan los acontecimientos relacionados con esta temática. Las universidades más prestigiosas son de ámbito internacional. Londres (Central Saint Martin), Nueva York (Parsons y FIT), París (La Chambre) o Milán (Marangoni)... cuentan con una oferta mucho mayor para estudiantes de Comunicación que quieren especializarse en moda, sobre todo en el ámbito privado.

El mercado de la moda, las grandes empresas, sociedades y grupos de accionistas están también ubicados en estos centros de la moda, lo que genera también mayor cantidad de información en los medios de comunicación. El análisis comparativo de la investigación podrá constatar el relevante espacio diario que los periódicos y revistas dedican a la moda en un foco primario como Nueva York, donde el cine se ha preocupado también de contarlo en conocidas películas como El diablo viste de Prada, Sexo en Nueva York, entre otras.

Es evidente que el periodismo de servicio y el periodismo especializado deben dar respuesta a este incipiente interés por unos contenidos que a veces ocupan toda una sección de "Sociedad". El primero, ofreciendo información requerida por la opinión pública, tanto desde el punto de vista social, como económico, educativo o de la salud. El segundo, analizando el tratamiento de los contenidos periodísticos sobre moda con claves especializadas como el background, la documentación, la explicación, el uso de las fuentes, los géneros y del lenguaje técnico, la argumentación y la crítica. Una tarea 
compartida cuyo objetivo final es apostar por la calidad informativa en los temas de interés público y del público.

En esta disyuntiva, investigadores y expertos realizan un análisis de la trayectoria histórica seguida por la moda. La relación entre la prensa y la moda se sitúa en los inicios del siglo XVIII, con unos antecedentes de crítica más que de aceptación. Como recoge Figueras (2005), cuando ocasionalmente se trataba en los textos las distintas formas de vestir, se hacía como algo ya conocido por todos y se aludía en forma satírica o formando parte de una denuncia de las costumbres de la época. Es ya entrado el siglo XVIII cuando cambia el tratamiento dado a la moda y esta empieza a aparecer en las revistas ilustradas, entre ellas, las revistas dirigidas a la mujer que han tenido una enorme importancia porque han reflejado los cambios y conquistas de la mujer a través de los tiempos.

Inglaterra fue uno de los focos pioneros en revistas que luchaban por reclamar los derechos de la mujer. Un ejemplo fue Lady Journal a la que más tarde siguieron las francesas Le journal des dames, Le courrier de le mode o Cabinet des modes que causó gran impacto porque junto a temas sobre moda informaba también sobre tendencias de decoración, joyas, mobiliario... En 1883 aparece en Francia la reconocida revista Vogue, que actualmente cuenta con ediciones en 20 países. Pero será en el siglo XX cuando proliferan las grandes revistas especializadas en moda, que presentan puestas en escena y fotos espectaculares y dedican especial atención a la alta costura y, más adelante, cuando se produce el proceso de democratización de la moda, al prêt à porter.

Terminada la Segunda Guerra Mundial, el panorama de edición de revistas cambia y se produce una auténtica apuesta por el mundo de la moda. En España se instalaron revistas de grupos internacionales como Elle, Marie Claire y Vogue, y más tarde Woman o Cosmopolitan, lo que supuso una difícil competencia para las revistas nacionales. Telva, made in Spain, cuenta con la ventaja de conectar más directamente con las aspiraciones de la mujer española.

El interés de la opinión pública por la moda lleva a las revistas del corazón y a los suplementos dominicales de periódicos a dedicar un importante espacio a una actividad que parecía reservada a las revistas especializadas, pero que cada vez en mayor medida ocupa las secciones de sociedad de la prensa generalista o los comentarios, magazines y tertulias de la radio y televisión.

\subsection{Diseñadores y periodistas. Lengua de Babel en busca de la especialización}

Condenados a entenderse, una frase que define en general la relación entre diseñadores y periodistas, una lengua de Babel con la que en definitiva se marca un objetivo común: vender. Vestidos o periódicos. La moda aglutina todos los ingredientes para que los medios de comunicación den a conocer un producto y enciendan en los ciudadanos el interés por informarse sobre los estilos y tendencias, así como tejidos, colores, marcas, prestigio social del diseñador. 
Como norma general, los expertos en cualquier ámbito científico o artístico critican la actitud poco rigurosa y a veces frívola del mundo mediático que destaca en capitulares un titular que puede hacer mucho daño a toda una trayectoria, proceso de investigación, descubrimiento... El periodista está sujeto a rutinas y debe responder a las cláusulas de economía y productividad que le exige su staff, un ritmo de trabajo que provoca rechazo e incluso negativa a la colaboración por parte de estudiosos de la ciencia (biólogos, médicos, astrónomos, químicos) o de historiadores y artistas (arquitectos, paleontólogos, diseñadores, interioristas, galeristas) para los que el factor tiempo y espacio se entiende forma diferente.

Decía Balenciaga, considerado casi por unanimidad el mejor modisto de todos los tiempos, "la moda es ante todo un arte. Un modisto tiene que ser arquitecto para los planos, escultor para las formas, pintor para el color, músico en la armonía y filósofo para crear estilo" (ápud Figueras, 2005: 38).

Es un secreto a voces que los creadores de moda califican la labor informativa como falta de rigor y especialización. El desconocimiento técnico de cronistas y críticos es el denominador común de las quejas de los profesionales del diseño. Mínima información, escasez de documentación, ausencia de un lenguaje técnico unido a periodistas generalistas que cubren un acontecimiento o evento de moda sin las nociones de especialización requeridas en su caso y en muchos otros dispuestos a contar la historia con tintes sensacionalistas. El modo de vida de las famosas top de las pasarelas, su anorexia o la presión a la que se ven sometidas o cómo se gestan los grandes imperios de la moda son ejemplos de contenidos que han suscitado la polémica y el morbo.

En las conclusiones provisionales del I Congreso sobre Comunicación Social de la Ciencia, celebrado en Granada (1999) se puntualiza que no es una cuestión nimia dirimir el carácter del lenguaje científico, o mejor, el del lenguaje con que se ha de comunicar la ciencia y en nuestro caso, el lenguaje técnico sobre ámbitos artísticos, culturales, sociales... Los expertos deberían vencer sus resistencias a hacer comprensibles sus investigaciones, a hablarle a la sociedad de un modo diferente a como hablan a sus colegas; los periodistas, por su parte, deberían hacer un esfuerzo para mejorar su preparación y buscar una mayor especialización (Esteve Ramírez y Fernández del Moral: 1999, 117-118).

El periodismo especializado se puede entender entonces como la mejor alternativa para informar sobre moda, explicarla desde la base de unos antecedentes (alta costura, el prêt a porter, le petite robe noir, el vintage, el new look, street style...) o sobre las últimas tendencias y nuevos perfiles profesionales del mundo del diseño de moda (cool hunting o "cazador de tendencias" y personal shopper o "asesor" en las compras de vestidos y accesorios). Además, la moda no aparece como algo independiente, inconexo. Es un movimiento inherente a un contexto, a una sociedad determinada, a unos gustos concretos.

El objetivo de los grandes diseñadores que han triunfado en este campo ha sido, ante todo, captar el espíritu de la época. En este sentido, el periodista especializado debe analizar el 
acontecimiento sin olvidar una mirada atrás, a la trayectoria del creador, a las propuestas de otras épocas con los llamados revivals, a lo innovador frente a lo básico... lo que le va a permitir explicar, argumentar, comparar y también valorar con una actitud crítica y fundamentada varias propuestas artísticas expuestas al éxito o al fracaso en función del juicio periodístico.

La apuesta por el periodismo especializado, con tantos defensores y detractores, parece ser la fórmula para el tratamiento adecuado de los contenidos y su divulgación. Dista mucho una información que elabora el periodista a partir de una relación directa con las fuentes especializadas (diseñadores, modelos, ilustradores, estilistas, responsables de comunicación y marketing de empresa...) de aquella otra centrada exclusivamente en el sensacionalismo, la prensa del corazón o la telebasura. Sin embargo, es difícil prescindir de personajes de reconocida fama y popularidad en los medios de comunicación que son la imagen de moda, las musas, el glamour para los creativos del diseño.

El periodista debe saber trasladar a sus lectores, a su audiencia, las connotaciones que rodean a este ámbito del arte. ¿Es la moda una alternativa sólo accesible a esferas sociales de alto nivel? ¿Qué estrategias se siguen para acercar la moda a la gente de la calle? ¿En qué manos se sustenta el imperio de la moda? ¿Qué tópicos rodean a las modelos? ¿Qué hay de cierto en definirlas como víctimas de su propia imagen? La labor del periodista especializado no es sólo informar, sino también formar a los públicos en la medida que promueve una actitud crítica y reflexiva ante la información. Preguntarse por qué es un referente en la especialización.

Es indiscutible, por tanto, el trabajo que a lo largo de la historia han desarrollado los medios como vía de acercamiento, de imagen, de prestigio pero también de crítica de la moda y de sus personajes más relevantes, los diseñadores. Figueras (2005) selecciona algunos casos relevantes en la historia de la moda: Diana Vreeland, futura editora de Vogue, contribuyó a encumbar a Chanel cuando llamó a la petite robe noir el "Ford de la moda". Aunque también los periodistas colaboraron en la confrontación de dos grandes del diseño, la Schiaparelli y Cocó. Según Ragna Fisher, que se encargaba de la sección de moda de varios periódicos escandinavos, "los desfiles de Chanel eran terriblemente serios y un poco aburridos y opinaba que "en la casa Schiaparelli uno se codea con la inspiración”. Sin embargo, Chanel había tenido un notable acierto: recoger las aspiraciones de la mujer de su época y hacerse solidaria de una nueva mujer que escalaba nuevos puestos en la sociedad, que invadía nuevos campos de trabajo. Por eso, su estrella duró más tiempo.

El new look de Dior fue un término ideado por una periodista americana. Los periodistas y sus críticas siempre han influido en la carrera de los modistos. A medida que ha pasado el tiempo, la figura del modisto se ha ido acercando a la gente y también la relación modistosprensa se ha hecho más cercana. Pertegaz, que siempre ha mantenido buenas relaciones con la prensa, decía: "Antes se creaba un mito de la figura del modisto. Era un personaje condicionado por la curiosidad. Si en su obra era brillante, tenía que responder al nivel de su obra. Ahora está más humanizada. La moda se ha vuelto más democrática y el creador ha seguido su ritmo" (ibídem). 
La simbiosis entre expertos y periodistas para divulgar la moda no es sólo recomendable sino necesaria porque es un derecho de los ciudadanos y un deber de los medios dar servicio y respuesta a la demanda de los públicos desde una perspectiva IFE (Información, Formación y Entretenimiento).

\subsection{El nuevo espacio de la moda en los medios}

También ha habido un cambio en la valoración del lugar que corresponde a la moda en los medios de comunicación y en la forma de presentarla y de informar. Como explica Erguizábal (2008: 29): “Los medios de comunicación transforman cualquier novedad en moda de un día; a cambio obtienen en un tiempo récord una difusión que en otras épocas habría costado décadas. Esto produce un efecto de desestabilización social desconocido hasta su implantación, provocando la consunción instantánea de cualquier tendencia, más la fragmentación y disparidad de los estilos". Y continúa el autor: "Los medios de comunicación han facilitado una descentralización de la moda. Ya no hay una tiranía geográfica como la hubo en otras épocas con Atenas, Roma, Bizancio, Florencia, Venecia, París, etc. Es cierto que la industria sigue instalada en ciudades como París, Milán, Londres, o Nueva York, pero no así la mano de obra ni tampoco las ideas. Las tendencias en música, vestimenta, bailes, pueden hoy tener lugar en cualquier rincón del mundo o en cualquier estrato social".

Hace algunos años su lugar estaba en las páginas femeninas o páginas de la mujer junto a labores, cocina... Actualmente se le da cabida en las páginas de "Sociedad" y "Cultura", entendiendo la importancia que el fenómeno de la moda tiene como referente histórico y social. En 1986, la revista Time dedicó una portada a Miyake y más tarde a Armani y Christian Lacroix. Esta presencia en medios de información general es un ejemplo de la relevancia que la moda y los diseñadores empiezan a tener en ámbitos no especializados y más divulgativos. Los géneros periodísticos por excelencia para informar sobre moda son la crónica y la crítica, que a menudo aparecen entrecruzadas, ya que la opinión o valoración del crítico se mezcla con la información del cronista social, con detalles sobre invitados a las colecciones y declaraciones del famoseo relativas a la vida personal (nuevas parejas, divorcios, matrimonios, futura maternidad) o profesional (estrenos, premios, giras artísticas, etc). La entrevista a los diseñadores, estilistas y modelos también es un género habitual en los medios de comunicación escritos y audiovisuales.

Los críticos de moda pueden ser una inyección de adrenalina para el lanzamiento y la consolidación del diseñador, pero en el caso opuesto puede significar el hundimiento y el fin de una carrera. La deferencia o el ataque de la prensa también ha sido motivo de debate entre los propios afectados. Kar Lagerfeld, el polifacético diseñador de Chanel, demostraba un desprecio total por las críticas. En una entrevista dijo: "Las críticas no me importan, me son indiferentes. Lo que me gusta es hacer colecciones y nadie puede persuadirme de que una colección es mala si me parece buena".

De lo que no cabe duda es que el periodista dedicado a la moda necesita una formación específica que en la actualidad se resuelve con la organización de congresos, máster, jornadas y seminarios, así como con actividades desarrolladas en las escuelas de moda. En 
el profesional especializado, capacitado para divulgar el mensaje de los protagonistas de la moda, descansa toda la confianza de quienes se esfuerzan día a día para vestir de elegancia y estilo a la sociedad de nuestro siglo.

\section{Aplicación práctica y trabajo de campo}

La investigación se gesta atendiendo a dos líneas fundamentales: una primera fase que permite aplicar la ficha VAP a los textos seleccionados en medios de comunicación de ámbito nacional e internacional. Una segunda fase se encuentra todavía en su etapa inicial y de la que iremos ofreciendo los resultados una vez que finalice el estudio.

Las estancias de investigación en universidades extranjeras, como Sacro Cuore de Milán o Fashion Institute of Technologie (FIT) de Nueva York, han inducido a una segunda fase cuyo objetivo es seguir profundizando en la idea de que el nivel de calidad del texto periodístico es directamente proporcional al nivel de formación del profesional que lo firma.

\subsection{Estructura de la investigación}

- La moda en los medios de comunicación.

- Formación e información periodística especializada en moda. Niveles de calidad.

- Análisis comparativo del tratamiento especializado en las crónicas de moda en la prensa americana y española durante septiembre de 2011.

\subsection{Hipótesis}

- La información sobre moda sigue siendo una asignatura pendiente en los medios de información general, aunque cada vez es mayor el espacio destinado en la prensa (periodismo especializado y periodismo de servicio).

- El tratamiento del texto periodístico carece de los índices de calidad exigibles a una información especializada.

- Es precisa una formación universitaria para futuros periodistas expertos en moda.

- La oferta de comunicación y moda en las universidades españolas es reducida en comparación con universidades extranjeras a pesar de la demanda de profesionales con este perfil.

\subsection{Metodología: Análisis de contenido y encuestas}

El método en la investigación es, sin duda, una fase clave. Gracias al método se podrán comprobar las hipótesis iniciales y alcanzar los objetivos propuestos. Hemos creído conveniente introducir las claves fundamentales del análisis de contenido así como de las técnicas cuantitativas y cualitativas que se van a usar en el estudio. 
Según Wimmer y Dominick (1996: 12-13), el empleo del método científico de investigación tiene como objetivo la aportación de valoraciones objetivas e insesgadas de los datos. Para examinar sistemáticamente cuestiones e hipótesis científicas, tanto los investigadores académicos como los de empresas privadas siguen un proceso encadenado y progresivo de ocho pasos: selección del problema, recabar información de estudios existentes, desarrollar hipótesis, establecer un método, recoger datos relevantes, analizar e interpretar los resultados, presentar los resultados de manera apropiada y repetir el estudio cuando sea necesario.

Existen claros matices diferenciadores entre el enfoque cuantitativo y cualitativo de los textos que los autores (ibídem: 145-146) recogen en sus estudios metodológicos:

- Papel del investigador: El investigador cualitativo apela a la objetividad y se sitúa al margen de los datos. El cualitativo es una parte integrante de los datos. De hecho, sin la participación activa del investigador, los datos no existirían.

- Diseño: En los métodos cuantitativos, la configuración del estudio se diseña antes de empezar, mientras que en los cualitativos el diseño evoluciona durante el proceso y se ajusta o modifica según va avanzando.

- Acotación del espacio: El investigador cuantitativo procura limitar las variables contaminantes o distorsionadoras mediante la realización de sus estudios en espacios controlados. El investigador cualitativo, en cambio, realiza sus trabajos en el propio terreno natural que rodea los asuntos observados, intentando captar, en la medida de lo posible, el curso normal de los acontecimientos.

- Instrumentos de medición: En la investigación cuantitativa, los instrumentos de medición existen aparte del investigador, pudiendo ser utilizados por otros analistas para seguir recopilando los datos en ausencia del investigador inicial. En contraposición, la investigación cualitativa tiene en el propio investigador su principal instrumento y ningún otro analista puede sustituir al primero.

- Formulación de teorías: Mientras el cuantitativista emplea la investigación para comprobar, confirmar o rechazar teorías, el cualitativista desarrolla teorías en simbiosis con su propio proceso de investigación.

¿Existe la posibilidad de conjugar ambas técnicas teniendo en cuenta las características del estudio? ¿Son compatibles las variables cuantitativas y cualitativas (dependientes e independientes) en una misma unidad de observación? ¿Es viable la aplicación de otros métodos complementarios del análisis de contenido?

La investigación cualitativa y cuantitativa han sido hasta el momento métodos independientes y específicos que se utilizaban en función del tipo de estudio en cuestión. Las investigaciones actuales en materia de comunicación social optan por la aplicación de técnicas cuantitativas y cualitativas, rompiendo con los procedimientos tradicionales que hasta ahora habían empleado la mayoría de los científicos e investigadores. Como señalan Miles y Huberman (1984: 20):

"Va siendo cada vez más difícil encontrar algún metodólogo sólidamente encastillado en una u otra epistemología aislada. Cada vez más cuantitativistas... 
emplean las estrategias naturalistas y fenomenológicas para complementar sus tests, encuestas y entrevistas estructuradas. Al otro lado, un creciente número de etnógrafos e investigadores cualitativos utilizan marcos conceptuales prediseñados y un instrumental estructurado previamente".

Conocidos los antecedentes y el contexto y con objeto de comprobar las hipótesis de partida, se puede diseñar una investigación con una doble vía:

- Analizar cualitativa y cuantitativamente la información sobre moda en diarios de información general españoles y extranjeros de referencia: diarios americanos (The New York Times) y españoles (El País).

- Realizar un estudio comparativo sobre la formación del periodista especializado en moda en universidades españolas y extranjeras. Máster de universidades americanas (Fashion Institute and Technologie de Nueva York) y españolas (Facultad de Comunicación de la Universidad de Sevilla)

\subsection{Herramienta VAP}

El diseño de la ficha de análisis permitirá conocer los niveles de calidad de los textos periodísticos con indicadores que marcan el valor agregado periodístico (VAP) que distingue unos textos de otros, por su tratamiento, su contraste, su coherencia, sus fuentes, su lenguaje o su visión analítica y crítica entre otros factores.

A través del análisis de la calidad periodística, no sólo se puede determinar qué textos pueden considerarse de calidad y cuáles no. También se pueden diagnosticar los males de la calidad periodística en la actualidad, partiendo de los propios textos y con la opción de modificar y mejorar las rutinas periodísticas, y con ello la formación de la conciencia crítica de la sociedad.

\subsection{Calendario previsto}

A partir de este momento se detectan dos investigaciones complementarias. Por un lado, el análisis de los niveles de calidad en prensa extranjera y española; por otro, los niveles de formación académica en estudios de Comunicación y Moda en universidades de ámbito internacional y nacional. Se trata de un trabajo arduo que necesitará sin duda de la colaboración al menos de una parte del equipo y que provisionalmente se define en dos fases:

Fase 1:

- Recopilación y selección de crónicas de moda en prensa americana desde el mes de septiembre de 2011 al mes de febrero de 2013.

- Recopilación de crónicas en la prensa española desde septiembre de 2011 a febrero de 2013.

- Estudio y análisis comparativo durante el curso el curso 2013-2014.

- Difusión de resultados prevista para el mes de septiembre de 2014. 
Fase 2:

- Entrevistas a docentes, alumnado, periodistas expertos en moda y profesionales del mundo de la moda, desde septiembre de 2011 a febrero de 2013.

- Revisión de los planes de ordenación docente de la universidad española frente a otras universidades extranjeras y localización de materias sobre Comunicación y Moda, desde el mes de septiembre de 2013.

- Análisis comparativo de los niveles de formación de periodistas especializados en moda en las universidades españolas y extranjeras citadas durante el curso 2013-2014.

- Difusión de resultados, prevista para el mes de septiembre de 2014.

\section{Primeros resultados}

Tal y como señalábamos antes, la investigación que nos ocupa tiene una etapa previa, anterior a la constitución del grupo de investigación, que se centra específicamente en los trabajos realizados por la autora del presente artículo; y una segunda etapa que comienza a partir de la constitución de nuestro grupo de investigación y consecuente presentación del proyecto de excelencia. Hasta el momento se pueden avanzar algunos resultados de encuestas y fichas de análisis de contenido que responden en una muestra menor (200 encuestas y 200 textos periodísticos analizados) a las hipótesis de partida.

En lo referente a las encuestas, se han repartido entre dos grupos de interés: profesionales del mundo de la moda y periodistas. Las encuestas cuentan con un total de 15 preguntas abiertas y cerradas de las que hemos elegido las siguientes:

\subsection{Los profesionales de la moda responden}

- ¿Qué requisitos exigiría a un buen periodista de moda? E1 79\% de los profesionales encuestados sitúa, en primer lugar, la formación y la documentación adecuada sobre los eventos, las colecciones, la historia de la moda, la cultura y las tendencias de la moda.

- ¿Qué aspectos más relevantes observa en el tratamiento de la información por parte de los medios? Un 60\% destaca el sensacionalismo, la superficialidad y la falta de documentación como características más relevantes, mientras que también un alto porcentaje (40\%) destaca que la moda todavía no es en España noticia para los medios de información general.

- ¿Suele ser habitualmente el mismo periodista el que cubre los eventos de moda? Esta cuestión ha levantado cierta polémica entre los profesionales porque el $90 \%$ se queja de la falta de periodistas especializados que conozcan el tema y de que se encarguen los temas de moda a periodistas inexpertos, nada informados y sin background sobre las colecciones presentadas. 
- ¿Considera que desde la Universidad se deben fomentar cursos y máster sobre moda? El $100 \%$ de los diseñadores encuestados contesta afirmativamente a esta cuestión porque entienden que la formación del periodista es clave para que los lectores se interesen, aprendan, sepan lo que compran y lo que representa la moda que consumen. Algunos además añaden la importancia de que el máster universitario cuente con la presencia de profesionales y expertos en moda sin obviar por supuesto al profesorado académico, ya que lo científico y lo profesional deben ser una simbiosis para que repercuta positivamente en el nivel de preparación de los futuros periodistas, publicistas, fotógrafos o empresarios dedicados a este ámbito.

\subsection{Los periodistas responden}

Han sido un total de 100 periodistas de prensa de ámbito local, regional y nacional los encuestados. No todos son cronistas de moda, sino que se han seleccionado al azar para ver qué interés en la moda tienen los propios medios y el seguimiento que se realiza de los eventos de moda.

- ¿Con qué asiduidad trata su medio este tema? El $70 \%$ de los encuestados considera que hasta hace unos años sólo se cubrían puntualmente en páginas de sociedad estos acontecimientos. Por ejemplo, cuando se celebra la pasarela Cibeles o Gaudí a nivel nacional o SIMOF a nivel específico de moda flamenca. Sin embargo, la tónica general es que cada vez la moda ocupa una ubicación más fija a la que se dedica mayor espacio, tanto en contenidos como en imágenes, a la vez que se detecta también un mayor interés de los lectores.

- ¿Cómo se ha formado en el mundo de la moda? El 93\% de los entrevistados no cuenta con una formación especializada en este ámbito, sino que le atrae como consumidores y posteriormente han hecho algún curso de experto o máster para conseguir una formación más completa. Su secreto es consultar mucha bibliografía, revistas y suplementos especializados y una formación actualizada sobre el tema.

- Si fuera diseñador, ¿qué requisitos exigiría a un buen periodista de moda? El 100\% ha respondido como primera opción la formación para poder escribir una buena crónica o crítica de moda. Un alto porcentaje señala como segunda opción la consulta con fuentes expertas y la objetividad frente al sensacionalismo y la frivolidad en los que a veces se convierte la información.

- Como periodista, ¿qué requiere a los profesionales de la moda? El 97\% los considera fuentes esenciales para poder informar sobre el tema, aunque a veces los definen como fuentes ávidas y demasiado interesadas en hablar o, por el contrario, reacias a facilitar la información. También es usual que los diseñadores depositen mucha confianza en sus agencias de información que hacen las veces de gabinetes de prensa que, en muchos casos, obstaculizan bastante la labor periodística.

- ¿Considera necesario la formación en comunicación y moda para los futuros profesionales de los medios? El 100\% entiende que es fundamental si se quiere ofrecer una información especializada, documentada, contextualizada que sepa llegar a los públicos y mostrarle los entresijos de la moda española e internacional. 


\subsection{Primeras fichas de análisis de contenido}

También en la fase previa de la investigación se han aplicado a dos periódicos como el The New York Times y El País la ficha de análisis y los resultados obtenidos de una muestra de 200 fichas (100 por periódico) han sido los siguientes:

Proceso de selección:

- Indicadores de selectividad: En total, 70 de las crónicas y críticas seleccionadas del The New York Times se han elegido por el medio teniendo en cuenta la relevancia de la noticia respecto al público lector, como foco de actualidad e interés. En El País igualmente más de un $85 \%$ de las noticias analizadas responden también a informaciones relacionadas con acontecimientos de interés para el público. El resto del porcentaje se dedica a entrevistas, reportajes, breves o análisis y columnas de opinión sobre el tema, sin que tengan que relacionarse con Fashion Weeks o VIP Events.

- Indicadores de acceso: En ambos periódicos se detecta un acceso y contraste con mayor número de fuentes expertas y siguen teniendo mucha presencia las fuentes oficiales, gubernamentales y empresariales por encima de las fuentes profesionales. Sin embargo, en el suplemento especializado "Smoda" de El País, se advierte un mayor contacto y contraste con las fuentes debido quizás al mayor espacio y tiempo que dedica frente a la falta de estos ingredientes en el periódico de información general.

- Indicadores de equidad: Los textos consultados del The New York Times se centran en el protagonista de la noticia (diseñador, modelo, estilista, bloguer, director de agencia) y en general se contextualiza y se hace referencia a antecedentes (trayectoria, dedicación actual del protagonista, última colección o publicación). En El País, en el 80\% de los géneros analizados existe una presencia excesiva del protagonista o protagonistas del evento. Sin embargo, se suele recurrir a la explicación e interpretación de los datos así como de los tecnicismos, algo que obvian las revistas especializadas en las que es complicado entender un contenido adornado con términos muy técnicos.

Proceso de creación:

- Indicadores de estilo: Las crónicas del The New York Times destacan en indicadores de estilo en todo lo que se refiere a una estructura novedosa (no en pirámide invertida) con mucha adjetivación, lenguaje técnico, uso de infográficos y grandes fotografías o fotonoticias. Usan el color en bastantes páginas e incluyen despieces, breves y destacados que dotan de gran dinamismo al conjunto de la información. Este formato se asemeja al de los suplementos y revistas especializadas de moda. El País, fiel siempre a su rigurosidad en el estilo opta por páginas similares al resto de secciones aunque no descarta alguna excepción puntual en el color o en el uso de fotografía.

- Indicadores de contenido: Son fundamentales para analizar el tratamiento de la información por parte del periodista. Aunque tanto The New York Times como El País están considerados periódicos de referencia internacional, se observa cómo depende mucho del profesional que trate la noticia para evaluar los niveles de background, 
profundidad, explicación y análisis de los contenidos, valoración crítica argumentada, contraste de fuentes o uso del lenguaje. Si se trata de un periodista, cronista o crítico de moda, especializado en el tema, dista mucho el resultado de aquellos contenidos superficiales, descontextualizados, faltos de antecedentes, de fuentes expertas o de elementos como infografías, gráficos, tablas comparativas o fotografías que complementen la información. Además, cuando el periodista que firma la crónica no es un especialista, se observan errores de importancia incluso en la estructuración temática y formal del género. Del total de textos analizados (cien por cada medio) en más del $45 \%$ en el The New York Times y del 50\% en El País, se evidencia que aunque suelen ser siempre los mismos periodistas los que cubren estos acontecimientos y cuentan con críticos de moda que manifiestan su opinión sobre ellos, el tratamiento de la información es mejorable si atendemos a los requisitos básicos de los textos especializados. De todas formas, los niveles de especialización detectados al azar en textos de otros periódicos son aún más bajos y rozan la especulación, el rumor, la falta de formación de las fuentes consultadas, pruebas de un ejercicio pobre de documentación por parte de los periodistas.

- Indicadores de énfasis: Tanto en uno como en otro periódico, los indicadores de énfasis responden sobre todo al interés humano y social de los eventos de moda, pero también se relacionan con temas polémicos (como la anorexia de las modelos, la crisis del sector o la situación económica de desahucio de muchos diseñadores) lo que conduce, si no responden al interés público, a informaciones que rozan el sensacionalismo y el amarillismo.

\section{Conclusiones}

Llegados a este punto y tras una primera baremación de los resultados se pueden confirmar algunas de nuestras hipótesis:

- En primer lugar, es cierto que la moda ocupa cada vez más un espacio mayor en los diarios de información general, según afirman los grupos encuestados. Sin embargo esta hipótesis no es directamente proporcional al tratamiento de calidad de los textos periodísticos, es decir, que se informe más sobre moda no significa que se informe correctamente, atendiendo a los ítems cuantitativos y cualitativos de los textos analizados, sobre todo si están firmados por periodistas ocasionales, mal documentados, que se centran en los titulares y descuidan las fuentes, el lenguaje, el contexto o las estructuras de género, optando por la superficialidad y la frivolidad informativa, defectos que los expertos académicos han vinculado al mundo de la moda.

- Por otro lado, es el momento de responder a la demanda de muchos de los estudiantes de cuarto y quinto de licenciatura de la Facultad de Comunicación de la Universidad de Sevilla e implementar los programas de estudios con el Primer Máster Emprendedores en Comunicación y Moda, con idea de formar a futuros profesionales expertos en estos ámbitos, que además puedan optar por crear su propia empresa en unos momentos difíciles para la economía mundial.

- Al igual que en el ámbito de la moda, el sector de la comunicación necesita de una formación universitaria que, sin obviar o desprestigiar lo académico, apueste por el 
desarrollo de capacidades profesionales que permita impulsar el autoempleo, la creación de nuevos modelos empresariales, la obtención de beneficios y la exportación de fórmulas exitosas ante los tiempos de crisis. "La dificultad favorece la creatividad" comenta Chon Toro, investigadora y profesora de Diseño de Moda Industrial de la Universidad Europea de Madrid. Por su parte, Cristina de Alzága, directora del Máster de Comunicación y Moda de la Universidad Francisco de Vitoria de Madrid, indica que "la crisis ha aguzado la imaginación y los cinco sentidos y se están viendo cada vez más propuestas y con una mayor originalidad en la línea de productos que se están lanzando al mercado" (apud García, 2012).

- Por tanto, la investigación sigue sus pasos para poder responder de forma más completa a todas nuestras hipótesis entre las que se encuentra también la afirmación de que la oferta universitaria en comunicación y moda en España es reducida si se compara con la de otros países, lo que redunda también en la falta de proyección empresarial de este sector a nivel internacional. Responder a estas hipótesis y alcanzar nuestros objetivos es todavía una tarea pendiente que necesita de un próximo capítulo.

\section{Fuentes consultadas}

Arriagada, E. (1999). "Buen periodismo y negocio. La ruta a la calidad". Cuadernos de información, núm. 13. Extraída el 3/IX/2013 desde http://comunicaciones.uc.cl/prontus fcom/site/artic/20050417/pags/20050417183757.html

AA. VV. (2008). Moda, comunicación y sociedad. Sevilla: Comunicación Social Ediciones.

Barthes, R. (2003). El sistema de la moda y otros escritos. Barcelona: Paidós.

Bovone, L. y González, A. (2012). Moda, identidad social y los actores. Oxford: Berg Publishers.

Buxbau, G. (2007). Iconos de la moda. Barcelona: El siglo XXI.

Castellano, J. (1993). "Una ventaja competitiva: el factor tiempo. El caso Inditex-Zara". Papeles de Economía Española, núm. 56, pp. 402-404.

Collado, R. (2008). “Cine y Moda: vestir a las estrellas”. En Moda, Comunicación y Sociedad. Sevilla: Comunicación Social Ediciones.

Dawber, M. (2005). Marcar tendencia. Ilustradores de moda contemporáneos. Barcelona: Gustavo Gili.

De Pablos, J. y Mateo, C. (2004). "Estrategias informativas para acceder a un periodismo de calidad en prensa y TV. Patologías y tabla de medición para recuperar la calidad en la prensa". Ámbitos, núm. 11-12, pp. 341-365. 
Debord, G. (2000). La sociedad del espectáculo. Valencia: Pre-Textos.

Erguizábal, R. (2008). "Estigmas de la Moda". En Moda, Comunicación y Sociedad. Sevilla: Comunicación Social Ediciones.

Erner, G. (2005). Victimas de la moda. Barcelona: Gustavo Gili.

Esteve Ramírez, F. y Fernández del Moral, J. (1999). Áreas de especialización periodística. Madrid: Fragua.

Figueras, J. (2005). Protagonistas de la moda. Madrid: Ediciones Internacionales Universitarias.

García, N. (2012, febrero 1). "Los jóvenes emprenden en moda". Extraída el 3/IX/2013 desde http://ecoaula.eleconomista.es/ecoaula-emprendedores/noticias/3713788/02/12/Los-jovenesemprenden-en-moda.html

García Gordillo, M.; Bezunartea Valencia, O. y Rodríguez Cruz, I. (2012). "El Valor Agregado Periodístico como herramienta para establecer los criterios definitorios de un periodismo de calidad". Extraída el 3/IX/2013 desde http://www.aeic2012tarragona.org/ cat $/$ abstracts3.asp? id_seccion $=6 \&$ id_slot $=59$

Gómez Mompart, J. y Palau Sampío, D. (2013). “El reto de la excelencia. Indicadores para medir la calidad periodística”, pp. 17-38. En Gómez Mompart, J.; Gutiérrez Lozano, J. y Palau Sampío, D. (eds.). La calidad periodística. Teorías, investigaciones y sugerencias profesionales. Valencia: Universitat Jaume I.

Klein, N. (2002). El poder de las marcas. Barcelona: Paidós.

Lurie, A. (2002). El lenguaje de la moda: una interpretación de las formas de vestir. Barcelona: Paidós.

Martínez Barreiro, A. (2004). "Moda y Globalización: de la estética de clase al estilo subcultural”. Revista Internacional de Sociología, vol. 62, núm. 39, pp. 139-166.

Miles, M. y Hubermann, A. (1994). Qualitative data analysis. An expanded sourcebook. Thousand Oaks: Sage.

Nueno, J.

_(2003). "El sector de la distribución textil en España”. Boletín Económico del ICE.

_(2001, marzo 21). "Examen a la moda". El País Semanal, pp. 152-158.

Riviere, M. (1994). Lo cursi y el poder de la moda. Madrid: Espasa Calpe.

Silverstein, M. y Fiske, N. (2006). La seducción del lujo. Barcelona: Deusto. 
Verdú, V. (2005). Yo y tú, objetos de lujo. Barcelona: Debate.

Wimmer, R. y Dominick, J. (1996). La investigación cientifica de los medios de comunicación. Una introducción a sus métodos. Barcelona: Bosch.

Witt, L. y Seoane, F. (2005). "Periodismo del futuro". Chasqui Revista Latinoamericana de Comunicación, núm. 91, págs. 28-35. 